\title{
Viewpoint
}

\section{Controle Biológico na Agricultura Brasileira}

\author{
José R. P. Parra
}

Departamento de Entomologia e Acarologia, Escola Superior de Agricultura "Luiz de Queiroz" - Universidade de São Paulo. 表=-Corresponding author: jrpparra@usp.br

Edited by: Rafael Major Pitta

Received: October 09, 2019. Accepted: October 31, 2019. Published: December 01, 2019.

Biological Control in Brazilian Agriculture

Abstract. We briefly discuss the present situation of biological control in Brazil and worldwide. The last decade has seen great progress, with several successful cases of pest control using macro- or microorganisms. Despite these advances in Brazil, although the country has progressed further than in other parts of the world, challenges remain to be overcome, including the "culture" of Brazilian farmers and the low availability of biological-control agents. As Brazil has become a leader in tropical agriculture over the last 40 years, we will most likely soon be leaders in tropical biological control as well.

Keywords: Entomopathogens, Macroorganisms, Sustainability.

A palavra mágica, hoje, é sustentabilidade. Muitos falam com entusiasmo sobre o assunto sem saber na realidade do que se trata. Entretanto, sempre o Controle Biológico (CB) é considerado um importante componente desta sustentabilidade.

$\mathrm{O}$ que é o CB? É assunto novo? Foi inventado (ou descoberto) no século XXI? Na realidade, CB é "coisa" muito antiga e os chineses já usavam formigas para controlar pragas há séculos atrás. Assim, todo organismo vivo ou planta tem o seu agente de mortalidade biótica. $\mathrm{E}$ isto fascina os "amantes da natureza" ao encontrarem, por exemplo, uma "joaninha" predando um pulgão numa determinada cultura.

Então, o CB é um "fenômeno natural que consiste na regulação de plantas e animais por agentes de mortalidade biótica". No início da humanidade, portanto, tudo estava em equilíbrio. Por necessidade de se alimentar, o homem desequilibrou o "sistema", plantando áreas extensas de soja, cana-de-açúcar, milho, algodoeiro, etc (Parra et al. 2002).

Hoje, atendendo a este clamor da sustentabilidade, busca-se restituir tal equilíbrio por meio do $\mathrm{CB}$. E este restituir o equilíbrio não é tão fácil como pensam os "amantes" da natureza mencionados.

Para utilizar o CB na busca da restituição do referido equilíbrio, o agricultor tem que receber um pacote tecnológico desenvolvido pela pesquisa e que pode ser variável, dependendo do tamanho da cultura.

Nesta busca pela utilização crescente do CB, aumentando de 10$15 \%$ no mundo por ano, buscam-se novos agentes além dos micro e macro-organismos que normalmente são utilizados na agricultura. Hoje já se falam e se utilizam os bioestimulantes, biofertilizantes e bioagentes (onde estão os macro e micro-organismos, semioquímicos, extratos de plantas, etc)

Há resistência à utilização de CB pela forte pressão de grandes empresas de agroquímicos e pela cultura do agricultor brasileiro que se acostumou com a aplicação de produtos químicos, ao longo de décadas, para controlar as pragas. Pode-se, por outro lado, dizer que não é só a cultura que impede a "entrada" dos produtos biológicos com uma força maior no mercado. Existem mitos, além da cultura, como pensar-se que a utilização do CB é uma medida fácil e a tratam com amadorismo e não profissionalismo como se faz para o controle químico. Outro mito existente é que o $\mathrm{CB}$ é uma medida de controle a longo prazo, diferentemente dos químicos que têm uma ação de "choque"; isto é "conversa" do passado, quando não se dispunham de técnicas de criação em grande escala de insetos (criações massais) e eram liberados pequenas quantidades de insetos ou patógenos e o controle era a longo prazo para culturas perenes ou semi-perenes. Hoje, com liberações inundativas, a resposta de controle é semelhante aos químicos e eficiente para culturas anuais e perenes. Um outro mito é que o CB deve resolver o controle de pragas isoladamente, quando na verdade ele deve fazer parte de um programa de "Manejo Integrado de Pragas" (MIP). Além disso, acredita-se em outro mito de que o custo do controle de pragas por medidas biológicas deve ser, para ser implantado, menor do que o preço do químico, esquecendo-se das vantagens ecológicas e sociais do CB (Parra 2019).

O que deve ser considerado é que a Agricultura Brasileira é diferente de outras partes do mundo, com os chamados sistemas de produção, com 2 a 3 colheitas anuais em certas regiões. Portanto, quando se fala que se utiliza muito o CB na Holanda ou Espanha, às vezes em $80-90 \%$ dos locais de plantio, deve-se lembrar que nestes locais tratam-se de controle em casas-de-vegetação.

Portanto, assim como fizemos com a nossa Agricultura e nos tornamos líderes em Agricultura Tropical nos últimos 40 anos, devemos desenvolver um Modelo de Controle Biológico para Regiões Tropicais; é isto que estamos fazendo, especialmente para campos abertos ("open fields") (Parra 2014).

É lógico que temos desafios, considerando-se o tipo de agricultura, incluindo a logística de armazenamento e transporte pela longa extensão territorial do Brasil; problemas de legislação (o pessoal está acostumado com legislação para agroquímicos); amostragem para liberação dos agentes de controle biológico; técnicas de liberação em grandes áreas; como "lidar" com áreas de transgênicos (hoje com mais de 50 milhões de ha no Brasil), disponibilidade dos agentes de controle biológico ao agricultor; técnicas de criação massal de insetos para macro-organismos com automatização; formulação para microorganismos, entre outros.

Um dos grandes momentos que começou a mudar a "cultura de agroquímicos" do agricultor brasileiro foi o registro de Helicoverpa armigera (Hubner, 1805) (Lepidoptera: Noctuidae) em 2013 no Brasil e naquele momento só se dispunham de opções biológicas, como o vírus e Trichogramma pretiosum Riley, 1879 (Hymenoptera: Trichogrammatidae) para controlar a praga. E para alguns foi frustrante, pois não foi possível atender a todos, pois, naquele momento, a disponibilidade dos agentes mencionados era limitada (Parra 2014).

Entretanto, o Controle Biológico no Brasil está, a despeito destes problemas, avançando mais do que em outras partes do mundo. Neste ano, o mercado de biológicos foi de 500 milhões de reais em nosso país 
e deverá chegar a 800 milhões em 2020. No mundo deverá passar dos 3 bilhões de dólares deste ano para 5 bilhões nos próximos anos.

No Brasil, temos uma boa massa crítica em $\mathrm{CB}$, formada nos últimos 40 anos, nos cursos de pós-graduação do país e um bom número de pesquisadores na área, atestado pela presença de 800 pessoas no último Siconbiol realizado em agosto de 2019 em Londrina, Paraná.

Os números são impressionantes, para macro-organismos com programas dentre os melhores do mundo, como em cana-de-açúcar com liberação em 2,2 milhões de ha tratados com Trichogramma galloi Zucchi, 1988 (Hymenoptera: Trichogrammatidae) e 3,5 milhões de ha com Cotesia flavipes (Cameron, 1891) (Hymenoptera: Braconidae) para controlar Diatraea saccharalis (Fabricius, 1794) (Lepidoptera: Crambidae). Existem diversas culturas utilizando Trichogramma spp. para lepidópteros em hortaliças e frutíferas, Orius insidiosus (Say, 1832) (Hemiptera: Anthocoridae) para tripes em casas-devegetação e em campos abertos, ácaros predadores para frutíferas, hortaliças e outro "produtos biológicos" como Telenomus podisi Ashmead, 1893 (Hymenoptera: Platygastridae) para controle de
Euschistus heros (Fabricius, 1798) (Hemiptera: Pentatomidae) em soja, em fase de registro, com alto potencial para 36 milhões de ha, bem como T. remus Nixon, 1937 (Hymenoptera: Platygastridae) e Trichogramma atoporivilia Oatman \& Platner, 1983 (Hymenoptera: Trichogrammatidae) para Spodoptera frugiperda (J. E. Smith, 1797) (Lepidoptera: Noctuidae) no milho e o complexo Spodoptera Guenée, 1852 na soja, por exemplo (Fig. 1) (Parra et al. 2002, Parra \& Coelho Júnior 2019).

Dentre os microorganismos, mais fáceis de serem aceitos pelo agricultor pela semelhança de utilização aos químicos na aplicação e pelo chamado "tempo de prateleira", onde pode ser armazenado antes de sua utilização, temos exemplos de milhões de ha tratados com Trichoderma harzianum Rifai (+ de 5 milhões de ha); Beauveria bassiana (Bals.-Criv.) Vuill. (1,5 milhões de ha); Metarhizium anisopliae (Metchnikoff) Sorokin (2,5 milhões de ha); Baculovírus (Baculoviridae) (200 mil ha); Bacillus spp. (1,5 milhões de ha), etc, nos últimos anos. Ao lado dos procedimentos básicos em Controle Biológico (introdução, conservação e multiplicação), o brasileiro inovou, nos

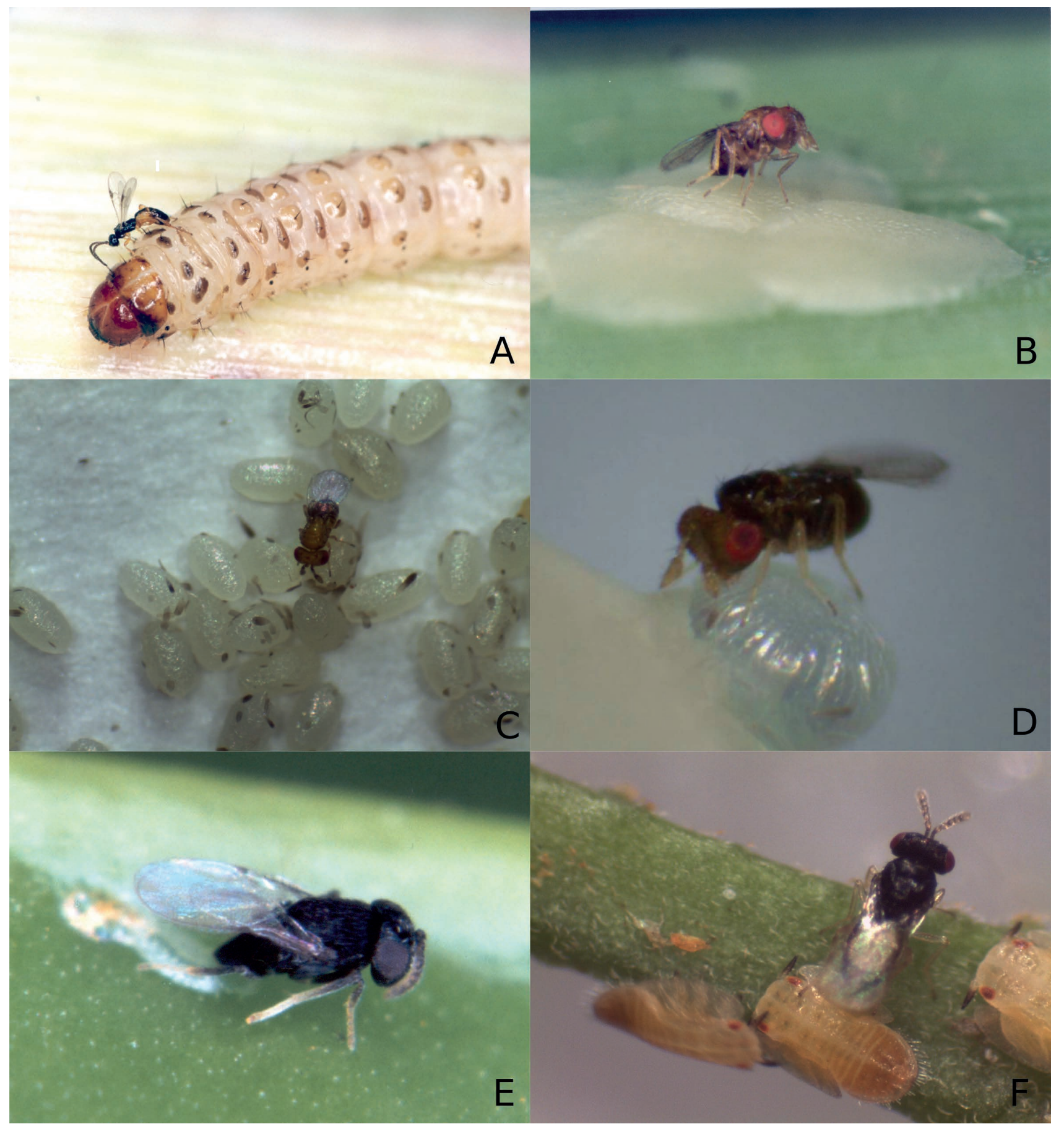

Figura 1. Exemplos de parasitoides bem-sucedidos no Brasil. A) Cotesia flavipes parasitando lagarta de Diatraea saccharalis. B) Trichogramma galloi parasitando ovos de Diatraea saccharalis. C) Trichogramma pretiosum sobre ovos de Anagasta kuehniella. D) Trichogramma atopovirilia sobre ovo de Anticarsia gemmatalis. E) Ageniaspis citricola parasitando lagartas de Phyllocnistis citrella. F) Tamarixia radiata parasitando ninfas de Diaphorina citri. 
últimos anos, em citros, para insetos transmissores de doenças. Assim, para controlar o vetor do HLB, o psilídeo Diaphorina citri Kuwayama, 1908 (Hemiptera: Liviidae) vem sendo utilizado o eulofídeo Tamarixia radiata (Waterston, 1922) (Hymenoptera: Eulophidae) liberado não nos pomares comerciais, mas nos focos primários da doença, ou seja, nas vizinhanças dos pomares [pomares abandonados após a erradicação de plantas devido à doença; áreas de murta (Murraya paniculata (L.) Jack, hospedeiro do psilídeo), áreas orgânicas e áreas de "fundo de quintal"]. Este manejo externo evitando a migração dos psilídeos infectados, tem dado excelentes resultados (cerca de $80 \%$ de controle), e são liberados após sua produção em 9 biofábricas do inimigo natural em São Paulo (e também no Paraná) (Parra et al. 2016, Diniz et al. 2019).

É fantástico o avanço do $C B$ no Brasil e o entusiasmo pela sua utilização. As grandes empresas de CB se instalaram no Brasil, vendo o potencial de utilização deste tipo de controle de pragas.

Este avanço tem muito a ver com a utilização da Agricultura 4.0, sendo que dos 2,2 milhões de ha tratados com $T$. galloi em cana-deaçúcar, $91 \%$ foram liberados com drones e avançam as pesquisas de amostragem com sensoriamento remoto para definição do momento de liberação dos agentes de CB.

Apenas uma chamada de atenção. Para avançarmos ainda mais, necessitamos de investimentos na área e, sobretudo, programas inter e multidisciplinares (com o aumento de massa critica na área), para termos uma perspectiva de lançamento de novos produtos biológicos, frutos destes programas inter e multidisciplinares, para o agricultor ávido pela utilização de novos produtos biológicos. 0 nosso portfólio de produtos biológicos precisa ser aumentado.

Poderíamos dizer que se há alguns anos atrás, falava-se que o futuro seria o $\mathrm{CB}$, podemos dizer sem medo de errar, que o futuro chegou!

\section{Referências}

Diniz, A. J. F.; Garcia, A. G.; Alves, G. R.; Reigada, C.; Vieira, J.M.; Parra, J. R. P. (2019). The enemy is outside: releasing the parasitoid Tamarixia radiata (Waterston) (Hymenoptera: Eulophidae) in external sources of HLB inocula to control the Asian citrus psyllid Diaphorina citri (Hemiptera: Liviidae). Neotropical Entomology. doi: 10.1007/s13744-019-00736-y

Parra, J. R. P. (2014). Biological Control in Brazil: An overview. Scientia Agricola, 71(5): 420-429. doi: 10.1590/0103-9016-2014-0167

Parra, J. R. P. (2019). Os mitos do Controle biológico. GBIO, 2: 4-5.

Parra, J. R. P.; Coelho Junior, A. (2019). Applied Biological Control in Brazil: From Laboratory Assays to Field Application. Journal of Insect Science, 19(2): 1-6. doi: 10.1093/jisesa/iey112

Parra, J. R. P.; Alves, G. R.; Diniz, A. J. F.; Vieira, J. M. (2016). Tamarixia radiata (Hymenoptera: Eulophidae) x Diaphorina citri (Hemiptera: Liviidae): Mass rearing and potential use of the parasitoid in Brazil. Journal of Integrated Pest Management, 7(5): 1-11. doi: 10.1093/ $\mathrm{jipm} / \mathrm{pmw} 003$

Parra, J. R. P.; Botelho, P. S. M.; Corrêa-Ferreira, B. S.; Bento, J. M. S. (Eds.). (2002). Controle biológico no Brasil: parasitoides e predadores. São Paulo: Manole. 